\title{
Possible association between androgenic alopecia and risk of prostate cancer and testicular germ cell tumor: a systematic review and meta-analysis
}

\author{
Weijun Liang ${ }^{\dagger}$, Liuying Song ${ }^{\dagger}$, Zheng Peng, Yan Zou and Shengming Dai ${ }^{*}$
}

\begin{abstract}
Background: A number of studies have investigated the association between androgenic alopecia (AGA) and cancer risk, but they have yielded inconsistent results. Therefore, this study was conducted to explore this controversial subject.

Methods: A literature database search was performed according to predefined criteria. An odds ratio (OR) or a hazard ratio (HR) with 95\% confidence intervals (Cls) was retained to evaluate the relationship between the incidence of cancer or cancer-specific mortality and categories of AGA. Then a pooled OR or HR was derived.

Results: The pooled results showed that no specific degree of baldness had an influence on the incidence of cancer or cancer-specific mortality. However, AGA, especially frontal baldness, with the incidence of testicular germ cell tumor $(T G C T)(O R=0.69 ; 95 \% \mathrm{Cl}=0.58-0.83)$. A significant increase of risk was observed in relation to high grade prostate cancer $(P C)(O R=1.42 ; 95 \% \mathrm{Cl} 1.02-1.99)$ and vertex with/without frontal baldness was associated with $P C$ risk.

Conclusions: The study results supported the hypothesis that AGA is negatively associated with TGCT risk and suggested an overlapping pathophysiological mechanism between them, while the viewpoint that AGA can be used as a phenotypic marker for PC risk was poorly supported.
\end{abstract}

Keywords: Androgenic alopecia, Prostate cancer, Testicular germ cell tumor, Risk, Association, Meta-analysis

\section{Background}

Androgenic alopecia (AGA) is characterized by nonscarring progressive reduction in the diameter, pigmentation, density, and length of hair from frontotemporal and/or vertex regions of the scalp in a distinctive pattern [1]. It is a type of androgen-dependent hair loss disorder that affects approximately $50 \%$ of men in their 50 s, [2] and its prevalence and extent tends to increase with age [3]. A vital alteration to the hair cycle for AGA is that the duration of the anagen phase decreases stepwise while that of the telogen phase increases, [4] but the

\footnotetext{
* Correspondence: daishm@sina.com

${ }^{\dagger}$ Equal contributors

Department of Clinical Laboratory, the Fourth Affiliated Hospital of Guangxi Medical University, No.1 Liushi Road, Liuzhou, Guangxi Zhuang Autonomous

Region 545005, People's Republic of China
}

pathogenesis of this disorder, as yet, is not fully understood. However, it has been fairly well established that androgens, mainly dihydrotestosterone (DHT) as major regulators, have critical effects on human androgensensitive hair follicles and may inhibit follicles on certain areas of scalp in genetically susceptible individuals and therefore causing AGA [5]. Testosterone, the principal androgen circulating in males, is converted to DHT by 5 - $\alpha$ reductase. It has been reported that $5 \alpha$-reductase inhibitors, such as finasteride, have increased scalp hair [6]. In addition, it has also been determined that heritability plays a critical role in the miniaturization of hair follicles leading to a change in the hair cycle $[7,8]$.

A high prevalence of abdominal obesity, hypertension, and lower high-density lipoprotein was found in patients affected by AGA [9]. Moreover, numerous studies have 
shown that AGA is implicated in an increased risk of metabolic syndrome [10] and coronary heart disease [11]. AGA is not simply recognized as an abnormal benign symptom with psychological effects and cosmetic impacts, but it has been represented as a forbear for future potential chronic diseases and therefore deserves attention. In consideration of similar pathophysiological mechanisms in terms of age dependency, genetic predisposition, and hormone dependency [12, 13], researchers have hypothesized a link between AGA and cancer risk, especially hormone-related cancer. Since cancer remains a worldwide public health issue that threatens human life, early diagnosis such as tumor screening could be an effective way to reduce the incidence of cancer. Yet, there are still some obstacles that hinder the wide application of tumor screening, for example, the lack of pertinence and the substantial consumption of healthcare resources. In this sense, it is beneficial to specify the high-risk groups to be screened so that it can reduce the costs, and that is why AGA is now being considered as a vital sign.

For the past two decades, a considerable number of publications have studied the relationship between AGA and hormone-related cancer, but they haven't yielded consistent results. Amoretti et al. [14] conducted a meta-analysis to reveal the relationship between AGA and prostate cancer in 2013, but there have been several published studies that involved more kinds of cancers. As a result, we conducted a systematic review and a comprehensive meta-analysis in order to further investigate the issue and identify potential sources of heterogeneity that might be confounders that have affected some existing conclusions.

\section{Methods}

\section{Search strategy and selection criteria}

We searched for all eligible publications that evaluated AGA and cancer risk in Embase and PubMed up to June 2016.The combined search strategy employed the terms androgenic alopecia, alopecia, baldness, bald or balding in combination with cancer, tumor, or neoplasm in combination with risk, incidence, or mortality. No language or country filters were imposed. The details of the searching terms were listed in (Additional file 1: Table S1). The selection criteria were as follows: (1) the studied participants were exposed to AGA, and there was no gender limitation; (2) the study evaluated the incidence or mortality of prostate cancer and testicular germ cell tumor; (3) the papers provided relative risks (RRs), including cancerspecific hazard ratios (HRs) or odds ratios (ORs) in combination with $95 \%$ confidence intervals (CIs), or provided related data could calculate RRs; and (4) the study design was unrestricted. If multiple publications reported overlapping data or the same data, the one with greater size or more information would be chosen. Reviews, comments, letters, notes, abstract and repeated literature case reports were all excluded.

\section{Data extraction and quality assessment}

Two reviewers (L.S and M.D) independently retrieved the information from all eligible records. The methodological quality was assessed by two authors (W.L and L.S) using the Newcastle-Ottawa Scale (NOS) with 0-3 scores defined as low quality, 4-6 scores as moderate quality, and 7-9 scores as high quality. For each study, the participant and study characteristics, number of subjects, type of controls, study design, follow-up time, type of cancer, means of AGA assessment, method of case confirmation, cohort/control selection, and AGA categories were extracted and transformed into the specially designed forms. Disagreements or uncertainties were resolved by the reviewers' re-verification of the data. If an agreement was not still reached, an additional adjudicator (S.D) was invited into the discussion.

\section{Data synthesis and statistical analysis}

If available, multivariate-adjusted risk estimates were used for each study; otherwise, unadjusted RRs, which were calculated according to exposure distributions given in the papers, were utilized. When a study only provided risk estimates from the comparison of a subset, i.e. a specific category of hair pattern such as frontal/vertex baldness with the group of no baldness, the alternative estimates were synthesized as the summarized estimates for overall exposure. If risk estimates were presented as RRs or ORs, combined estimates were generated using the method proposed by Hamling et al. [15], and if they were presented as HRs, a fixed-effect model was conducted.

Considering potential interactions, studies were stratified by the different designs of the studies with the effects estimated by HRs for cohort studies or ORs for case-control studies. As the ORs for case-control studies approximate the RRs in cohort studies with low incidence and effects estimated generally approaching 1.0, the combination of ORs and RRs was permitted [16]. According to the results of inter-study heterogeneity appraisal using $X^{2}$-based $Q$ statistics and $I^{2}$ for statistical significance of heterogeneity, pooled ORs and HRs with 95\% CI were calculated using a fixed-effect model (Mantel-Haenszel method) or random-effect model (DerSimonian-Laird method). A $P$ value of $\mathrm{Q}$ statistics $>0.10$ and $\mathrm{I}^{2}<50 \%$ indicated little heterogeneity. Sensitivity analysis was performed to assess the influence of a single trial in the meta-analysis estimated by sequential omission of individual trials. Publication bias was assessed with a funnel plot and the Egger regression. An overall meta-analysis was carried out in all included studies, and then a specific type of cancer with 
over two articles was included as the subtype that was performed for further meta-analysis. Prespecified subgroup analyses were performed by, reference age (20, 30,40 , or 45) for baldness assessment, pattern of baldness (frontal, vertex, vertex with frontal, vertex with/ without frontal, and frontal with vertex), amount of baldness [1st stage: I; 2nd stage: II, IIa; 3rd -4th stage: III, IIIa, III-vertex, IV, Iva; 5th-7th stage: V, Va, VI, VII which were measured by Hamilton-Norwood scale (see Additional file 2: Figure S1)], type of control, baldness assessment type (by self-reporting and by trained observers) and age of the case.

A two-sided $P<0.05$ was considered statistically significant. The STATA version 12.0 (StataCorp LP, College Station, Texas, USA) was used for statistical analysis.

\section{Results}

\section{Eligible studies}

The literature retrieval identified 1562 records in Pubmed and 4476 in Embase. Ultimately, 20 publications [17-35] were finally selected for the study; the flow diagram was presented in Fig. 1. The results of methodological quality assessment indicated that all included records were of high quality (More details were shown in Additional file 3: Table S2 and Table S3). All data generated or analysed during this study are included in this published article [and its Additional file 4: Excel S1].

\section{Baseline characteristics}

In total, six cohort studies [17, 18, 20, 23, 24, 27] and 14 case-control studies $[19,21,22,25,26,28-36]$ were included in the present systematic review and metaanalysis. Among these, two cohort studies $[17,18,37]$ were conducted on PC-specific mortality. In the case-control studies, ten studies addressed PC [21, 22, 26, 28, 30-32, 34-36], and four addressed TGCT [19, 25, 29, 33]. PC and TGCT were performed as the subtype for further meta-analysis. The baseline characteristics were shown in Table 1.

\section{Systematic review and meta-analysis}

The pooled results indicated that any kind of baldness had no influence on the PC-specific mortality in a randomeffect model, with an HR $=1.07$ (95\% CI 0.43-2.64) and moderated heterogeneity $\left(\mathrm{I}^{2}=69.2 ; P=0.071\right)$. Twenty observational studies were involved in assessing the relationship between AGA and cancer incidence, including 6 cohort studies [17, 18, 20, 23, 24, 27] and 14 case-control studies $[19,21,22,25,26,28-36]$. The cohort study of Hawk et al. [27] with the effects estimated by RRs was combined with case-control studies in the pooled analyses. A negative association was shown when all studies were pooled, with an HR $=0.99$ (95\% CI 0.91-1.09). Depending on the particular method of baldness assessment, the studies were separated into two subsets. The first subset included 10 studies [20,22, 26, 27, 29, 31-35] that assessed baldness by self-reporting, and the second subset included $3[21,25,28]$ studies where it was assessed by trained observers. No association was consistent in the two subsets. A summary of the results was presented in (Additional file 5: Table S4).

\section{Analysis of TGCT}

Four case-control studies [19, 25, 29, 33] that assessed the influence of AGA on the incidence of TGCT showed a negative association $(\mathrm{OR}=0.69$; $95 \% \mathrm{CI} 0.58$ $0.83 ; P<0.001$ ) with little evidence of heterogeneity (Fig. 2a). When the studies were stratified by histological subtypes,

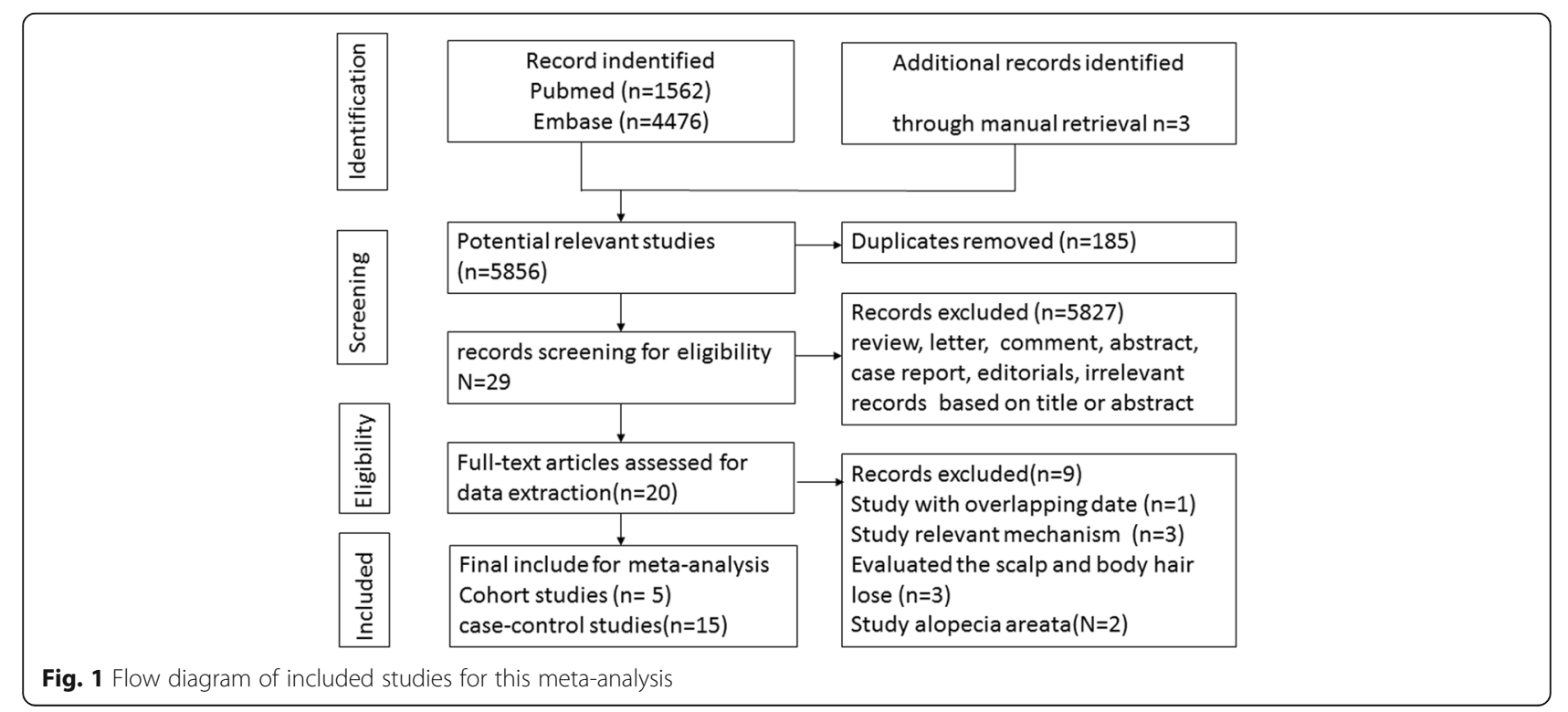




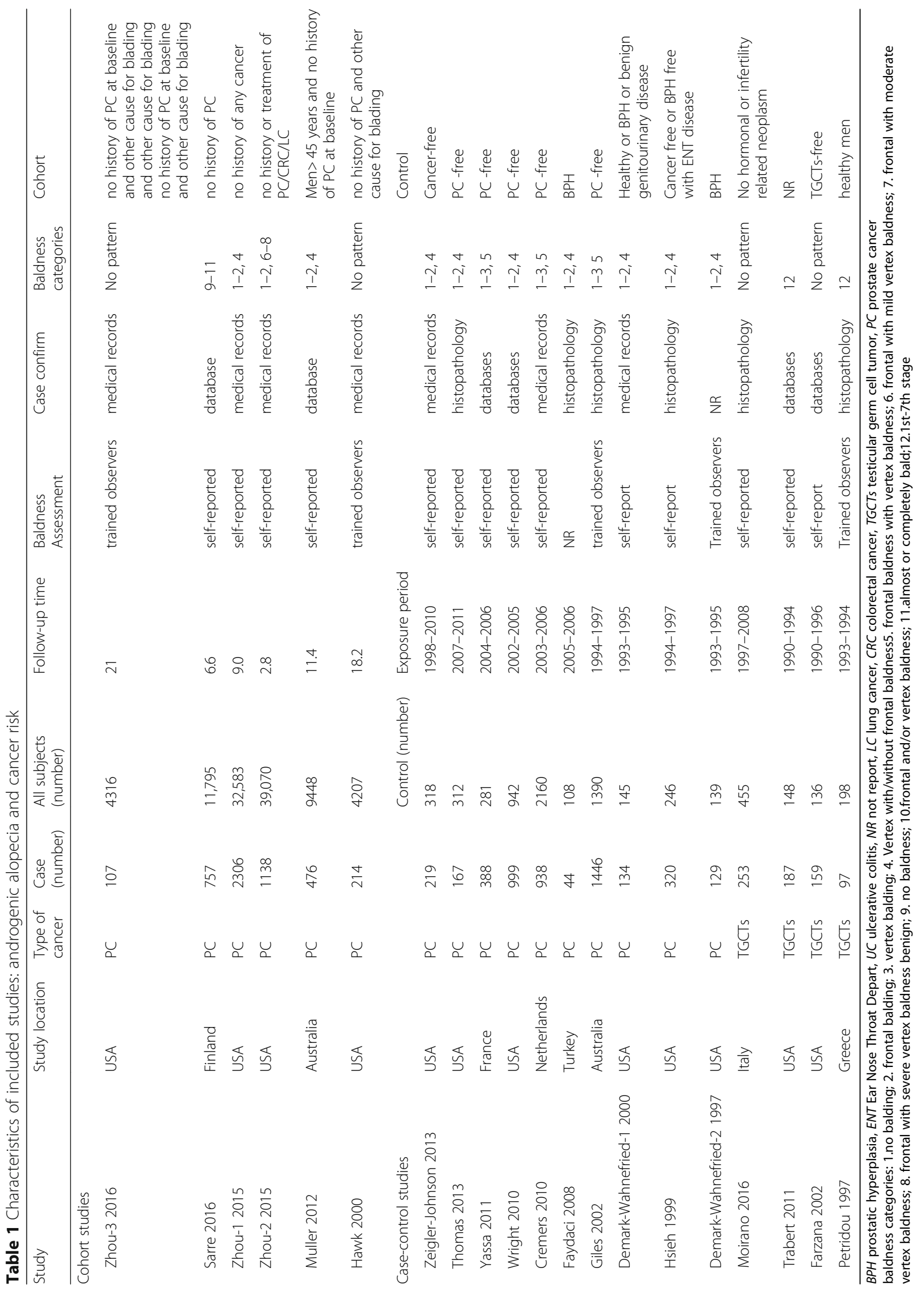



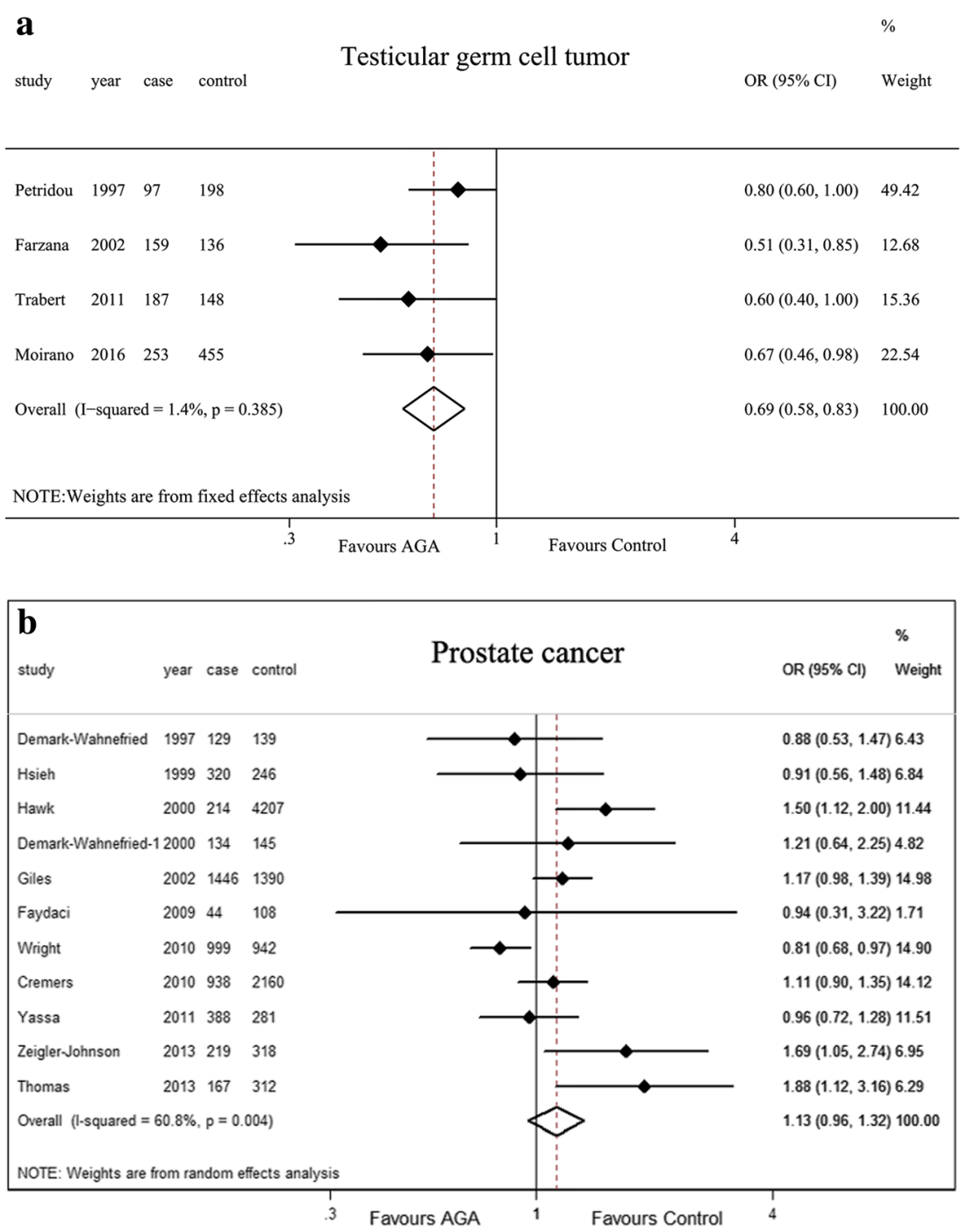

c

study

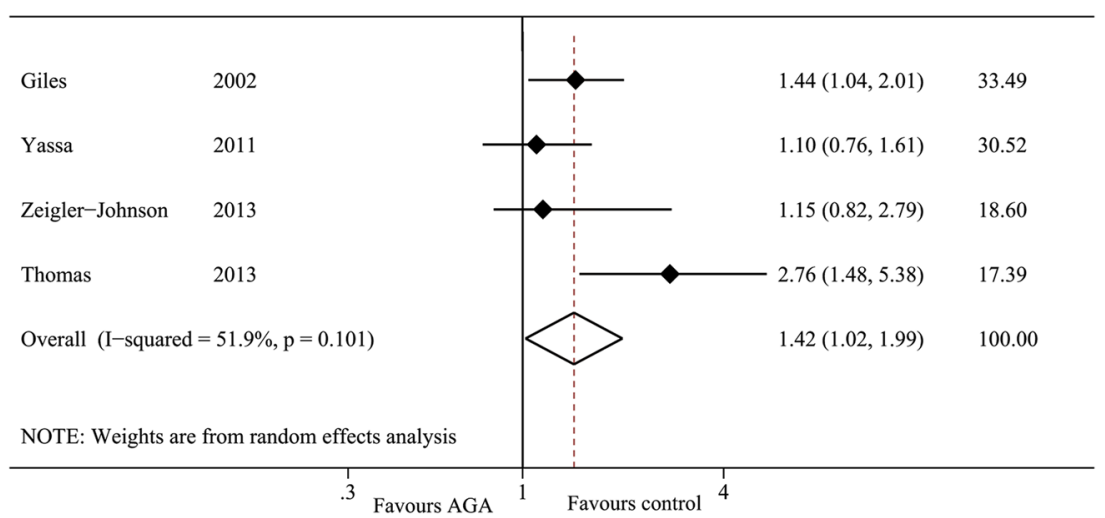

Fig. 2 Forest plots of any AGA and the risk of PC and TGCT incidence for case-control studies: a for TGCT incidence; $\mathbf{b}$ for PC incidence; and $\mathbf{c}$ high grade $P C$ incidence 
the results were consistent and more strongly evident in nonseminoma. When the studies were stratified by different degree of baldness on the basis of the Hamilton-Norwood scale, hair loss at 2nd stage was negatively correlated with TGCT risk compared to that at $1 \mathrm{ST}$ stage $(\mathrm{OR}=0.46 ; 95 \%$ CI $0.30-0.72 ; P=0.001)$. A summary of the results was presented in Table 2.

\section{Case-control studies \& analysis of PC}

The pooled OR for the 11 studies [21, 22, 26-28, 30-32, 34-36] that assessed the association between any AGA and the risk of PC was 1.13 (0.96-1.32) (Fig. 2b). However, when studies on PC stratified by different grades/stages $[22,28,34,35]$ were combined, a significantly increased risk was observed in high grade $\mathrm{PC}(\mathrm{OR}=1.42$; $95 \% \mathrm{CI}$ 1.02-1.99; $P=0.038$ ) (Fig. 2c). The effect of size demonstrated a moderate statistical heterogeneity among studies of PC. When studies of PC were stratified by grades, no evidence of heterogeneity was observed. All the metaanalysis results of association between AGA and incidence of $\mathrm{PC}$ are listed in Table 3.

\section{Different patterns of baldness}

Based on the Hamilton-Norwood Scale, the 8 study subsets $[21,22,26,27,30,32,33,35]$ and the 4 study subsets $[25,28,31,34]$ were categorized for male pattern baldness, among which 3 variables (none or little baldness, frontal baldness and vertex with/without frontal baldness) were used for the first subset and 4 variables (none or little baldness, frontal, vertex without frontal baldness, and frontal with vertex) for the second subset. Vertex with/without frontal baldness was associated with $\mathrm{PC}(\mathrm{OR}=1.29 ; 95 \% \mathrm{Cl} 1.03-1.61 ; P=0.029)$.

\section{Different reference age}

A total of two studies evaluated AGA at reference age 20 [31, 34], five at age 30 [22, 32, 34-36], and four at age $40[31,34-36]$, respectively. No association was established for participants with AGA at ages 20, 30, and 40 , and these analyses yielded moderate heterogeneity.

\section{Different age of case}

Three studies [22, 28, 32] calculated the age-stratified association. AGA was not associated with the risk of cancer incidence in either younger men $(<60$ years of age) or older men ( $\geq 60$ years of age).

\section{Different types of controls}

As controls, five studies [28, 31, 32, 34, 35] selected PCfree participants, two $[21,30]$ selected prostatic hyperplasia $(\mathrm{BPH})$ participants, and the others selected cancer-free or benign disease participants. No significant relationship was found between AGA and PC risk when the study was stratified by the different types of controls.

\section{Cohort studies \& analysis of PC}

When four cohort studies [17, 18, 23, 24] were combined, the pooled results revealed that AGA had no relationship with prostate cancer in a random-effect model, with an $\mathrm{HR}=0.99(0.94-1.05)$ and moderated heterogeneity $\left(\mathrm{I}^{2}=<0.1 \%\right)$. In other subgroup analysis, the results were consistent.

\section{Sensitivity analysis and publication bias}

Sensitivity analysis confirmed that no individual study influenced the overall results (data not shown). There was no evidence of publication bias in this meta-analysis indicated by the Begg's funnel plot and Egger's tests (Fig. 3).

\section{Discussion}

This systematic review and meta-analysis involved a total of 10,935 cases from 21 observational studies. Amoretti et al. [14] conducted a meta-analysis to examine the association between AGA and the incidence of PC, but more studies have been published to indicate its relation to other kinds of cancer. Besides, this meta-analysis also evaluated the relationship between AGA and the

Table 2 Meta-analysis results of association between AGA and incidence of testicular germ cell tumor

\begin{tabular}{|c|c|c|c|c|c|c|}
\hline \multirow[t]{2}{*}{ Study characteristics } & \multirow{2}{*}{$\begin{array}{l}\text { Number } \\
\text { of studies }\end{array}$} & \multirow[t]{2}{*}{$\mathrm{OR}(95 \% \mathrm{Cl})$} & \multirow[t]{2}{*}{$P$ value } & \multirow{2}{*}{$\begin{array}{l}\text { Effect } \\
\text { model }\end{array}$} & \multicolumn{2}{|c|}{ Heterogeneity } \\
\hline & & & & & $\mathrm{P}^{2}(\%)$ & $P$ value \\
\hline Overall & 4 & $0.69(0.58-0.83)$ & $<0.001$ & fixed & 1.4 & 0.385 \\
\hline Seminoma & 4 & $0.71(0.55-0.93)$ & 0.011 & fixed & $<0.1$ & 0.545 \\
\hline Nonseminoma & 4 & $0.57(0.44-0.74)$ & $<0.001$ & fixed & 43.2 & 0.153 \\
\hline \multicolumn{7}{|l|}{ Baldness assessment type } \\
\hline self-reported & 3 & $0.61(0.47-0.78)$ & $<0.001$ & fixed & $<0.1$ & 0.697 \\
\hline \multicolumn{7}{|c|}{ Different amount of baldness } \\
\hline 2nd vs. 1st stage & 2 & $0.46(0.30-0.72)$ & 0.001 & fixed & $<0.1$ & 0.639 \\
\hline 3 rd -4 th vs. 1 st stage & 2 & $0.67(0.40-1.13)$ & 0.135 & fixed & $<0.1$ & 0.794 \\
\hline 5th -7 th vs. 1 st stage & 2 & $0.46(0.20-1.05)$ & 0.065 & fixed & $<0.1$ & 0.797 \\
\hline
\end{tabular}


Table 3 Meta-analysis results of association between AGA and incidence of prostate cancer

\begin{tabular}{|c|c|c|c|c|c|c|}
\hline \multirow[t]{2}{*}{ Study characteristics } & \multirow{2}{*}{$\begin{array}{l}\text { Number } \\
\text { of studies }\end{array}$} & \multirow[t]{2}{*}{ OR(95\% Cl) } & \multirow{2}{*}{$\begin{array}{l}P \\
\text { value }\end{array}$} & \multirow{2}{*}{$\begin{array}{l}\text { Effect } \\
\text { model }\end{array}$} & \multicolumn{2}{|c|}{ Heterogeneity } \\
\hline & & & & & $P^{2}(\%)$ & $P$ value \\
\hline Case-control studies & 11 & $1.13(0.96-1.32)$ & 0.150 & random & 60.8 & 0.004 \\
\hline high grade ${ }^{a}$ & 3 & $1.46(0.89-2.51)$ & 0.172 & random & 67.3 & 0.047 \\
\hline high grade ${ }^{b}$ & 4 & $1.42(1.02-1.99)$ & 0.038 & random & 51.9 & 0.101 \\
\hline high stage & 2 & $1.29(0.61-2.72)$ & 0.503 & random & 59.4 & 0.117 \\
\hline \multicolumn{7}{|l|}{ Baldness assessment type } \\
\hline self-reported & 8 & $1.15(0.94-1.41)$ & 0.178 & random & 66.5 & 0.002 \\
\hline trained observers & 2 & $1.13(0.93-1.36)$ & 0.215 & fixed & 6.7 & 0.300 \\
\hline \multicolumn{7}{|l|}{ Different patterns of baldness } \\
\hline Frontal vs. No & 10 & $1.03(0.86-1.23)$ & 0.786 & random & 48.5 & 0.042 \\
\hline Vertex with/without Frontal vs. no baldness & 6 & $1.29(1.03-1.61)$ & 0.029 & fixed & 9.8 & 0.353 \\
\hline Vertex without Frontal vs. no baldness & 3 & $1.23(0.95-1.60)$ & 0.124 & random & 58.1 & 0.092 \\
\hline Frontal with Vertex vs. no baldness & 4 & $1.01(0.89-1.15)$ & 0.899 & fixed & $<0.1$ & 0.524 \\
\hline \multicolumn{7}{|l|}{ Different reference age } \\
\hline 20 & 2 & $1.28(0.59-2.75)$ & 0.533 & random & 81.4 & 0.020 \\
\hline 30 & 5 & $1.25(0.83-1.88)$ & 0.289 & random & 79.5 & 0.001 \\
\hline 40 & 4 & $1.00(0.78-1.29)$ & 0.988 & random & 52.4 & 0.098 \\
\hline \multicolumn{7}{|l|}{ Different age of case } \\
\hline$<60$ & 3 & $1.11(0.92-1.35)$ & 0.264 & fixed & 27.8 & 0.251 \\
\hline$\geq 60$ & 3 & $1.03(0.68-1.55)$ & 0.902 & random & 71.2 & 0.031 \\
\hline \multicolumn{7}{|l|}{ Different type of control } \\
\hline PC-free & 5 & $1.07(0.87-1.31)$ & 0.516 & random & 73.3 & 0.005 \\
\hline $\mathrm{BPH}$ & 2 & $1.20(0.72-2.01)$ & 0.490 & random & 72.0 & 0.002 \\
\hline Cohort studies & 4 & $0.99(0.94-1.05)$ & 0.714 & Fixed & $<0.1$ & 0.521 \\
\hline Subtypes of cancer & 5 & $1.02(0.93-1.13)$ & 0.656 & random & 59.5 & 0.043 \\
\hline Frontal vs. no baldness & 2 & $1.01(0.93-1.10)$ & 0.756 & fixed & $<0.1$ & 0.831 \\
\hline aggressive & 2 & $1.01(0.94-1.14)$ & 0.812 & fixed & $<0.1$ & 0.876 \\
\hline nonaggressive & 2 & $1.07(0.96-1.20)$ & 0.194 & fixed & $<0.1$ & 0.701 \\
\hline Frontal with Vertex vs. no baldness & 2 & $1.05(0.96-1.14)$ & 0.289 & fixed & $<0.1$ & 0.914 \\
\hline aggressive & 2 & $1.04(0.93-1.17)$ & 0.490 & fixed & $<0.1$ & 0.641 \\
\hline nonaggressive & 2 & $1.01(0.89-1.14)$ & 0.894 & fixed & $<0.1$ & 0.483 \\
\hline reference age $=45$ & 2 & $1.01(0.94-1.071)$ & 0.858 & fixed & $<0.1$ & 0.780 \\
\hline
\end{tabular}

$B P H$ prostatic hyperplasia

high grade: Gleason score 7-10; high grade ${ }^{\mathrm{b}}$ : Gleason score 8-10 and Gleason score 7-10; high stage: T-stage 3-4; aggressive prostate cancer: Gleason score 7-10 or regional/distant metastases (SEER summary stage) or fatal prostate cancer

mortality of cancer. Moreover, several subgroup analyses were conducted to evaluate whether the association varied by subtype of PC or TGCT, reference age for baldness assessment, pattern of baldness, type of control, and age of the case, and to minimize potential confounding biases.

Cases of AGA demonstrated a 31\% decrease in the incidence of TGCT compared to those with no baldness. The sample size was not sufficient as there were only four studies included in the subset but little heterogeneity was shown. AGA may be regarded as a surrogate of cumulative androgen status which was considered as the result of its components such as exogenous hormones, endogenous hormonal levels, hormonal metabolism, or individual sensitivity to hormones. TGCT is significantly different from PC at the onset age. High risk for TGCT often occurs at ages 20-45 while it occurs at later ages for PC. It has been reported that circulating testosterone, DHT, and E2 declined gradually during male aging [38]. Thus, age differences both in the incidence of different kinds of cancer and the androgen status account for a complex interplay of these four components. 

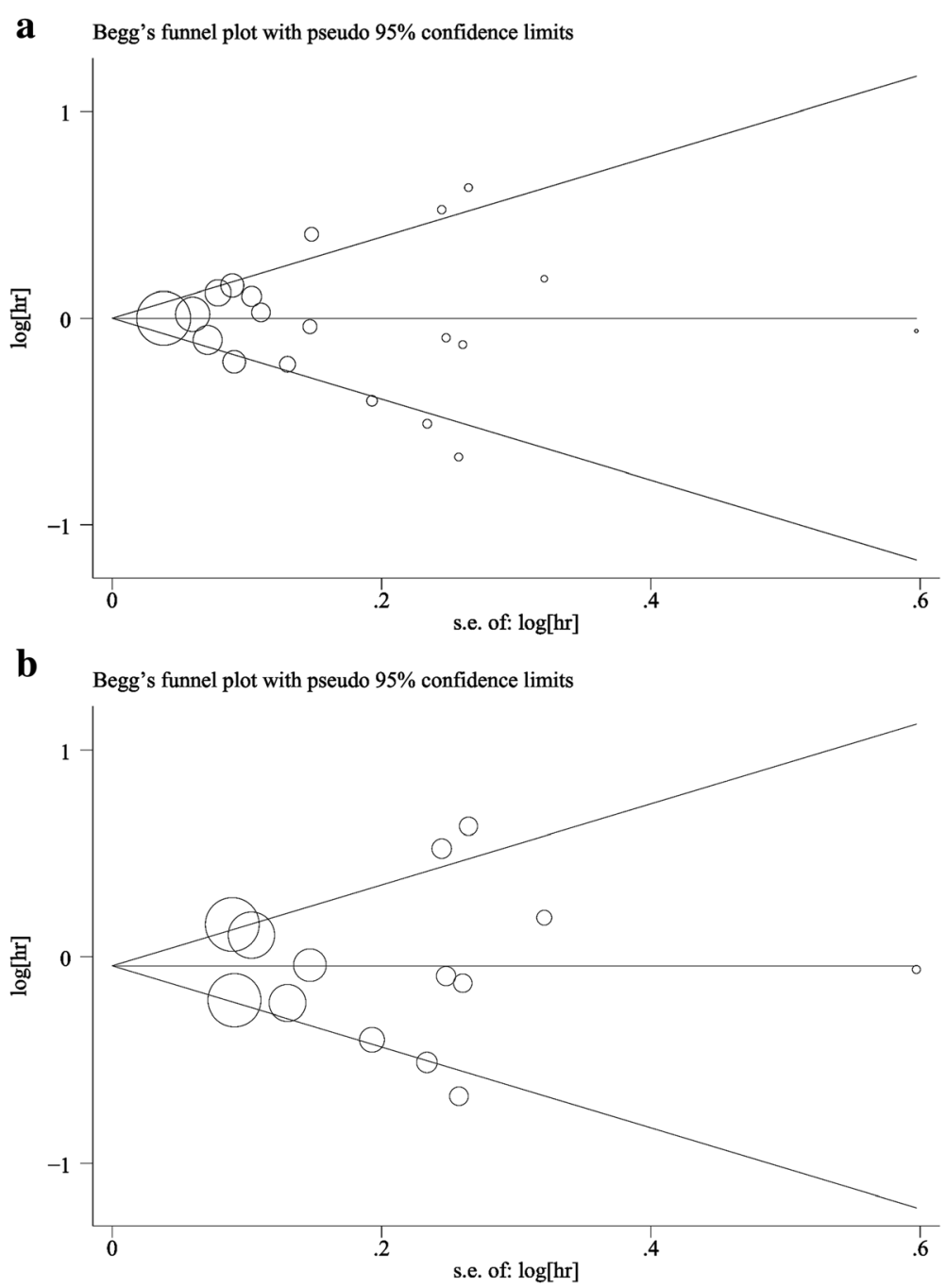

Fig. 3 Begg's funnel plots for publication bias of the relative risk of cancer incidence: a for all included studies; $\mathbf{b}$ for case-control studies; and $\mathbf{c}$ for cohorts

In addition, androgen receptor and androgen metabolic pathway genetic variation studies showed that Ser312Asn polymorphism of the luteinizing hormone receptor was linked to an increased relative risk of PC [39] and a decreased relative risk of TGCT [40]. This suggested that androgen expression and metabolism might have tissue-specific effects. Moreover, testosterone and DHT appeared to be tissue-specific as well [41]; DHT played a vital role primarily in prostate and scalp, while testosterone appeared to function in spermatogenesis, muscle, and bone. These findings suggested that a complex interaction may partly explain the reason why AGA, as a surrogate of high androgen, has been implicated in different cancer but has shown conflicting results. AGA might reflect androgen status more directly and be less affected by other factors, thus being inversely related to tumorigenesis in TGCT. In histologic specific analyses on TGCT, the pooled results indicated that AGA exposure was significantly inversely related to the risks of developing both seminoma and nonseminoma. This relationship was more predominant among nonseminoma with less heterogeneity. Given that nonseminoma is often diagnosed at ages $25-29$ on average, which is 10 years earlier than seminoma [42], the risk of TGCT decreased due to hormonal related factors during this time, and they may be more relevant to nonseminoma. Also, it was possible that these differences were caused by an insufficient sample size and inadequate statistical power for stratified analysis.

For 11 of the included studies, the association of AGA with PC was not evident in the overall population, which was consistent with the previous study [42]. Some authors speculated that the earlier onset of AGA, compared with its later onset, is a risk factor for developing PC. However, all the pooled results at different AGA time points $(20,30,40$, and 45$)$ were negative. Yet, the 
interference of another potential source of bias, such as inadequate sample size, recall and selection bias, and study design, could not be ruled out. But, the present results could not support this interference. Also, the pooled results for baldness assessment type, age of case, and control selection were thought to be major factors. Coincident with the overall results, no subset analyses could establish a link between AGA and the incidence of PC. Thus, it is plausible that the overall results are robust. In addition, moderate inter-study heterogeneity was found to be consistent in case-control studies which suggested that there might be some other confounders or bias that accounted for inter-study heterogeneity. Several studies [22, 28, 34, 35] categorized the cases of PC into two grades according to Gleason scores, but the cut-off scores were not congruent. A negative result was achieved when included studies only focused on high grade PC with Gleason scores of 7-10. It was interesting to note that the result turned out to be positive when a study on high grade PC with Gleason scores of 8-10 was included. However, the pooled results showed AGA was not linked to aggressive PC (defined as Gleason scores of 7-10, regional/distant metastases, or fatal prostate cancer) without a difference in any baldness pattern in the cohort studies. The Gleason score was regarded as a good indicator of PC aggressiveness. Gleason 7 was divided into Gleason $4+3$ and $3+4$. Pathologically advanced $\mathrm{PC}$ and poor prognosis were more common in the first of the two. In our present meta-analysis, however, an agreement on the exact grade of PC with Gleason score 7 was not reached. A new Gleason grading system was proposed wherein Gleason scores $\leq 6$ were lumped into prognostic grade group I, the score of $3+4=7$ into group II, the score of $4+3=7$ into group III, the score of $4+4=8$ into group IV, and scores of 910 into group $V[43,44]$. Thus, whether the less aggressive Gleason 7 cases account for the negative results or not needed to be confirmed and a new Gleason grading system should be applied in further studies.

When it came to different categories of baldness, the results showed that the vertex pattern with/without frontal baldness was related to PC risk, but the frontal pattern was not. On the other side, baldness at 2nd stage which amounted to frontal baldness was related to TGCT risk, while the other categories were not. As a result, a dose-response relationship could not be obtained. If these relationships were real, they may be possibly explained by non-linear correlations between the degree of AGA and the circulating androgen status. It was difficult to explain how the results turned to be negative in the PC, when vertex without frontal baldness and vertex with frontal baldness were regarded as independent patterns in the pooled studies. Also, no specific pattern of AGA showed any link to PC risk in the cohort studies.
The pathophysiological difference among the patterns of AGA was yet unknown, so a reasonable explanation could not be provided. In addition, the reference age of AGA was different in the included studies; however, Muller et al. [20] found that vertex AGA at age 40 was not associated with the risk of PC; at age 55, the vertex AGA group had a higher hazard of prostate cancer; at ages $60-70$, the HR was not discernible from 1; and at age 75 , the hazard of prostate cancer was lower. This indicated that the association between AGA and PC was by nature age-variant and could not be sufficiently described by a single, age-invariant estimate of relative risk. Thus, the association might be masked by inconsistent AGA assessment age. Moreover, finasteride is a type II 5 - $\alpha$ reductase inhibitor and is commonly used to treat AGA, [37] which could theoretically decrease the incidence of PC [45]. Another important point was that numerous epidemiologic studies have shown that AGA was associated with cardiovascular disease [46]. However, most of these studies lacked information on the connection of comorbidity and the use of finasteride. Therefore, this connection was potentially a major source of bias that could influence the final results, and the positive results should be interpreted with caution.

In this meta-analysis, only two of the included studies examined the association of AGA and PC-specific mortality, which showed that inner-study heterogeneity was moderate. Hence, more research work was needed to confirm these findings.

Nevertheless, several limitations of this study must be acknowledged. First, despite several subgroup analyses to be performed, significant heterogeneity was generally observed. Given the differences of the studies in race, age, participants' lifestyle, information collection method, sample size, duration of follow-up and so on, heterogeneity was not avoidable. Second, the number of stratified analyses was so limited that might result in invalid statistical analyses in those groups. Third, although most of the studies used multivariate statistical models to calculate the estimated RRs, the number and content of the adjusted confounders varied in each trial, which might lead to imprecision in the results. But, the most multivariable adjusted-effect estimates were chosen for analysis to minimize the confounding biases. Besides, several sources of bias, such as inherent limitations, unmeasured confounding, and the typical bias of observational studies, could have affected the observed results. Therefore, welldesigned and more comprehensive studies are still needed to further evaluate the relationship between AGA and the risk of cancers.

\section{Conclusions}

The results support the hypothesis that AGA is associated with a reduction of TGCT incidence by altering 
testicular development and they also suggest that there is a common pathogenic pathway. For PC, positive results are only observed in vertex patterns of AGA and high grade $\mathrm{PC}$, while the viewpoint that AGA can be used as a phenotypic marker for PC risk is poorly supported. In this sense, future studies should be conducted to confirm the conclusions, as well as to evaluate the potential value of this association, which may offer a reference for establishment of predictive models.

\section{Additional files}

Additional file 1: Table S1. Review methodology for meta-analysis. (DOC $29 \mathrm{~kb}$ )

Additional file 2: Figure S1. Male balding patterns base on the Hamilton-Norwood scale. (TIFF 356 kb)

Additional file 3: Table S2. NOS scores of cohort studies. Table S3. NOS scores of case control studies. (DOC 86 kb)

Additional file 4: Excel S1. Extracted raw data in the meta-analysis. (XLSX $16 \mathrm{~kb}$ )

Additional file 5: Table S4. Meta-analysis results of association between androgenic alopecia and incidence of cancer. (DOCX $17 \mathrm{~kb}$ )

\section{Abbreviations}

AGA: Androgenic alopecia; BPH: Prostatic hyperplasia; Cls: Confidence intervals; DHT: Dihydrotestosterone; HRs: Hazard ratios; NOS: NewcastleOttawa Scale; ORs: Odds ratios; PC: Prostate cancer; RRs: Relative risks; TGCT: Testicular germ cell tumor

\section{Acknowledgements}

We owe our thanks to Yujie Huang and Meiyu Dai for their work on revising and data extracting in this manuscript.

\section{Funding}

Key Laboratory Construction of Tumor Diseases Prevention in Liuzhou, Guangxi (No.2014G020403) provides financial supports in the design of the study and collection, analysis, and interpretation of data and in writing the manuscript.

\section{Availability of data and materials}

All data generated or analyzed during this study are included in this published article and its additional files.

\section{Further information}

Not applicable.

\section{Authors' contributions}

Conception and Design: WL and SD; Extraction of Data: LS; Quality assessment: WL and LS; Drafting the Article: LS, YZ and ZP; Revising It for Intellectual Content: WL, LS and SD; Final Approval of the Completed Article: WL, LS and SD. All authors read and approved the final manuscript.

\section{Ethics approval and consent to participate}

Not applicable.

\section{Consent for publication}

Not applicable.

\section{Competing interests}

The authors declare no conflict of interest.

\section{Publisher's note}

Springer Nature remains neutral with regard to jurisdictional claims in published maps and institutional affiliations.
Received: 15 July 2016 Accepted: 6 March 2018

Published online: 12 March 2018

\section{References}

1. Piraccini B, Alessandrini A. Androgenetic alopecia. G Ital Dermatol Venereol. 2014;149(1):15-24.

2. Kaliyadan F, Nambiar A, Vijayaraghavan S. Androgenetic alopecia: an update Indian J Dermatol, Venereol Leprol. 2013;79(5):613-25.

3. Hamilton JB. Patterned loss of hair in man: types and incidence. Ann N Y Acad Sci. 1951;53(3):708-28.

4. Randall VA. Androgens and hair growth. Dermatol Ther. 2008;21(5):314-28.

5. Kaufman KD. Androgen metabolism as it affects hair growth in androgenetic alopecia. Dermatol Clin. 1996;14(4):697-711.

6. Blumeyer A, Tosti A, Messenger A, Reygagne P, Del Marmol V, Spuls PI, Trakatelli M, Finner A, Kiesewetter F, Trüeb R. Evidence-based (S3) guideline for the treatment of androgenetic alopecia in women and in men. J Dtsch Dermatol Ges. 2011;9(s6):S1-S57.

7. Nyholt DR, Gillespie NA, Heath AC, Martin NG. Genetic basis of male pattern baldness. J Investig Dermatol. 2003;121(6):1561-4.

8. Li R, Brockschmidt FF, Kiefer AK, Stefansson H, Nyholt DR, Song K, Vermeulen SH, Kanoni S, Glass D, Medland SE. Six novel susceptibility loci for early-onset androgenetic alopecia and their unexpected association with common diseases. PLoS Genet. 2012;8(5):e1002746.

9. Gopinath $\mathrm{H}$, Upadya GM. Metabolic syndrome in androgenic alopecia. Indian J Dermatol Venereol Leprol. 2016;82(4):404-8.

10. Wu D, Wu L, Yang Z. Association between androgenetic alopecia and metabolic syndrome: a meta-analysis. Zhejiang Da Xue Xue Bao Yi Xue Ban. 2014;43(5):597-601.

11. Trieu N, Eslick GD. Alopecia and its association with coronary heart disease and cardiovascular risk factors: a meta-analysis. Int J Cardiol. 2014;176(3): 687-95.

12. Henderson BE, Ross RK, Pike MC, Casagrande JT. Endogenous hormones as a major factor in human cancer. Cancer Res. 1982;42(8):3232-9.

13. Folkerd EJ, Dowsett M. Influence of sex hormones on cancer progression. J Clin Oncol. 2010;28(26):4038-44.

14. Amoretti A, Laydner $H$, Bergfeld W. Androgenetic alopecia and risk of prostate cancer: a systematic review and meta-analysis. J Am Acad Dermatol. 2013;68(6):937-43.

15. Hamling J, Lee $P$, Weitkunat $R$, Ambühl M. Facilitating meta-analyses by deriving relative effect and precision estimates for alternative comparisons from a set of estimates presented by exposure level or disease category. Stat Med. 2008;27(7):954-70

16. Zhang J, Yu KF. What's the relative risk? A method of correcting the odds ratio in cohort studies of common outcomes. JAMA. 1998;280(19):1690-1.

17. Zhou CK, Levine PH, Cleary SD, Hoffman HJ, Graubard BI, Cook MB. Male pattern baldness in relation to prostate Cancer-specific mortality: a prospective analysis in the NHANES I epidemiologic follow-up study. Am J Epidemiol. 2016:183(3):210-7.

18. Sarre S, Määttänen L, Tammela TL, Auvinen A, Murtola TJ. Postscreening follow-up of the Finnish prostate Cancer screening trial on putative prostate cancer risk factors: vitamin and mineral use, male pattern baldness, pubertal development and non-steroidal anti-inflammatory drug use. Scand J Urol. 2016:50(4):267-73.

19. Moirano G, Zugna D, Grasso C, Lista P, Ciuffreda L, Segnan N, Merletti F, Richiardi L. Baldness and testicular cancer: the EPSAM case-control study. Andrology. 2016;4(2):251-6.

20. Muller DC, Giles GG, Sinclair R, Hopper JL, English DR, Severi G. Agedependent associations between androgenetic alopecia and prostate cancer risk. Cancer Epidemiol Biomark Prev. 2013;22(2):209-15.

21. Demark-Wahnefried W, Lesko SM, Conaway MR, Robertson CN, Clark RV, Lobaugh B, Mathias BJ, Strigo TS, Paulson DF. Serum androgens: associations with prostate cancer risk and hair patterning. J Androl. 1997; 18(5):495-500.

22. Zeigler-Johnson C, Morales KH, Spangler E, Chang BL, Rebbeck TR. Relationship of early-onset baldness to prostate cancer in african-american men. Cancer Epidemiol Biomark Prev. 2013;22(4):589-96.

23. Zhou CK, Littman AJ, Levine PH, Hoffman HJ, Cleary SD, White E, Cook MB. Male pattern baldness in relation to prostate cancer risks: an analysis in the VITamins and lifestyle (VITAL) cohort study. Prostate. 2015;75(4):415-23.

24. Zhou CK, Pfeiffer RM, Cleary SD, Hoffman HJ, Levine PH, Chu LW, Hsing AW, Cook MB. Relationship between male pattern baldness and the risk of 
aggressive prostate cancer: an analysis of the prostate, lung, colorectal, and ovarian Cancer screening trial. J Clin Oncol. 2015;33(5):419-25.

25. Petridou E, Roukas Kl, Dessypris N, Aravantinos G, Bafaloukos D, Efraimidis A, Papacharalambous A, Pektasidis D, Rigatos G, Trichopoulos D. Baldness and other correlates of sex hormones in relation to testicular cancer. Int J Cancer. 1997;71(6):982-5.

26. Hsieh CC, Thanos A, Mitropoulos D, Deliveliotis C, Mantzoros CS, Trichopoulos D. Risk factors for prostate cancer: a case-control study in Greece. Int J Cancer. 1999;80(5):699-703.

27. Hawk E, Breslow RA, Graubard BI. Male pattern baldness and clinical prostate cancer in the epidemiologic follow-up of the first National Health and nutrition examination survey. Cancer Epidemiol Biomark Prev. 2000;9(5):523-7.

28. Giles GG, Severi G, Sinclair R, English DR, McCredie MR, Johnson W, Boyle P, Hopper UL. Androgenetic alopecia and prostate cancer: findings from an Australian case-control study. Cancer Epidemio Biomarkers Prev. 2002:11(6):549-53.

29. Walcott FL, Hauptmann M, Duphorne CM, Pillow PC, Strom SS, Sigurdson AJ. A case-control study of dietary phytoestrogens and testicular cancer risk. Nutr Cancer. 2002;44(1):44-51.

30. Faydaci G, Bilal E, Necmettin P, Fatih T, Asuman O, Ugur K. Baldness, benign prostate hyperplasia, prostate cancer and androgen levels. Aging Male. 2008;11(4):189-92.

31. Cremers RG, Aben KK, Vermeulen SH, Den Heijer M, Van Oort IM, Kiemeney LA. Androgenic alopecia is not useful as an indicator of men at high risk of prostate cancer. Eur J Cancer. 2010;46(18):3294-9.

32. Wright JL, Page ST, Lin DW, Stanford JL. Male pattern baldness and prostate cancer risk in a population-based case-control study. Cancer Epidemiol. 2010;34(2):131-5.

33. Trabert B, Sigurdson AJ, Sweeney AM, Amato RJ, Strom SS, McGlynn KA. Baldness, acne and testicular germ cell tumours. Int J Androl. 2011;34(4 PART 2):e59-67.

34. Yassa M, Saliou M, de Rycke Y, Hemery C, Henni M, Bachaud JM, Thiounn N, Cosset JM, Giraud P. Male pattern baldness and the risk of prostate cancer. Ann Oncol. 2011;22(8):1824-7.

35. Thomas JA, Antonelli JA, Banez LL, Hoyo C, Grant D, Demark-Wahnefried W, Platz EA, Gerber L, Shuler K, Eyoh E, et al. Androgenetic alopecia at various ages and prostate cancer risk in an equal-access multiethnic case-control series of veterans. Cancer Causes Control. 2013;24(5):1045-52.

36. Demark-Wahnefried W, Schildkraut JM, Thompson D, Lesko SM, Mclntyre L, Schwingl P, Paulson DF, Robertson CN, Anderson EE, Walther PJ. Early onset baldness and prostate cancer risk. Cancer Epidemiol Biomarkers Prev. 2000; 9(3):325-8.

37. Mella JM, Perret MC, Manzotti M, Catalano HN, Guyatt G. Efficacy and safety of finasteride therapy for androgenetic alopecia: a systematic review. Arch Dermatol. 2010;146(10):1141-50.

38. Handelsman DJ, Yeap B, Flicker L, Martin S, Wittert GA, Ly LP. Age-specific population centiles for androgen status in men. Eur J Endocrinol. 2015; 173(6):809-17.

39. Ingles SA, Liu SV, Pinski J. LHRH and LHR genotypes and prostate cancer incidence and survival. Int J Mol Epidemiol Genet. 2013:4(4):228.

40. Kristiansen W, Aschim E, Andersen J, Witczak O, Fosså S, Haugen T. Variations in testosterone pathway genes and susceptibility to testicular cancer in Norwegian men. Int J Androl. 2012;35(6):819-27.

41. Khera M, Crawford D, Morales A, Salonia A, Morgentaler A. A new era of testosterone and prostate cancer: from physiology to clinical implications. Eur Urol. 2014:65(1):115-23.

42. Gatta G, Trama A. Epidemiology of testicular Cancer. In: Colecchia M, editor. Pathology of testicular and penile neoplasms. New York City: Springer; 2016. p. $3-18$

43. Chen N, Zhou Q. The evolving Gleason grading system. Chinese journal of cancer research $=$ Chung-kuo yen cheng yen chiu. 2016;28(1):58-64.

44. Epstein Jl, Egevad L, Amin MB, Delahunt B, Srigley JR, Humphrey PA. The 2014 International Society of Urological Pathology (ISUP) consensus conference on Gleason grading of prostatic carcinoma: definition of grading patterns and proposal for a new grading system. Am J Surg Pathol. 2016;40(2):244-52.

45. Vickers AJ, Savage CJ, Lilja H. Finasteride to prevent prostate cancer: should all men or only a high-risk subgroup be treated? J Clin Oncol. 2010;28(7): 1112-6.

46. Yamada T, Hara K, Umematsu H, Kadowaki T. Male pattern baldness and its association with coronary heart disease: a meta-analysis. BMJ Open. 2013; 3(4):e002537.

\section{Submit your next manuscript to BioMed Central and we will help you at every step:}

- We accept pre-submission inquiries

- Our selector tool helps you to find the most relevant journal

- We provide round the clock customer support

- Convenient online submission

- Thorough peer review

- Inclusion in PubMed and all major indexing services

- Maximum visibility for your research

Submit your manuscript at www.biomedcentral.com/submit 